\title{
HYBRID DEER
}

The winter of 1984 - 1985 was a fairly severe winter and a deer feeding program was instituted. Having a fair number of deer around (mostly Mule Deer and some White-tailed) took part in this program. It was surprising how soon the deer knew feed was being put out for them at evening and morning chore time. As if by magic at $8: 30$ in the morning and 4:30 in the afternoon deer appeared out of the tree shelterbelts. Those that had gone back to the riverbreaks were coming on the run, as if they were racing to see who could get there first.

When spring weather arrived the deer spent most of their time in the riverbreaks, and much less time at the farm. In the fall of $1985-1986$, when the first bad weather arrived, a small herd came in and were searching for food in the area that they had been fed the previous winter.

I was surprised to see that two of the Mule Deer does had White-tail fawns nursing on them. One had two and the other had one. These were soon weaned but stayed close to mothers until spring.

The next fall, 1986 - 1987, they back again, but the mothers had Deer fawns. Two of the previol spring White-tails were bucks. were quite independent, the th doe, followed her mother and si The fall of $1987-1988$ the samt were around, except for one White-tail bucks. It had either si away or was taken during the hi season. This season of 1988 the de back again and the surviving $b$ now a proud specimen and th arrived with a youngster.

I am positive that these three de were nursing on Mule Deer d 1985 - 1986 are White-tail and Deer crosses. It is hard to believ Mule Deer would adopt other Deer let alone those of another $\mathrm{SF}$ We have had a White-tail buck as ing with the Mule Deer for $s$ years. - Sig Jordheim, White Bea atchewan. SOL $3 \mathrm{LO}$
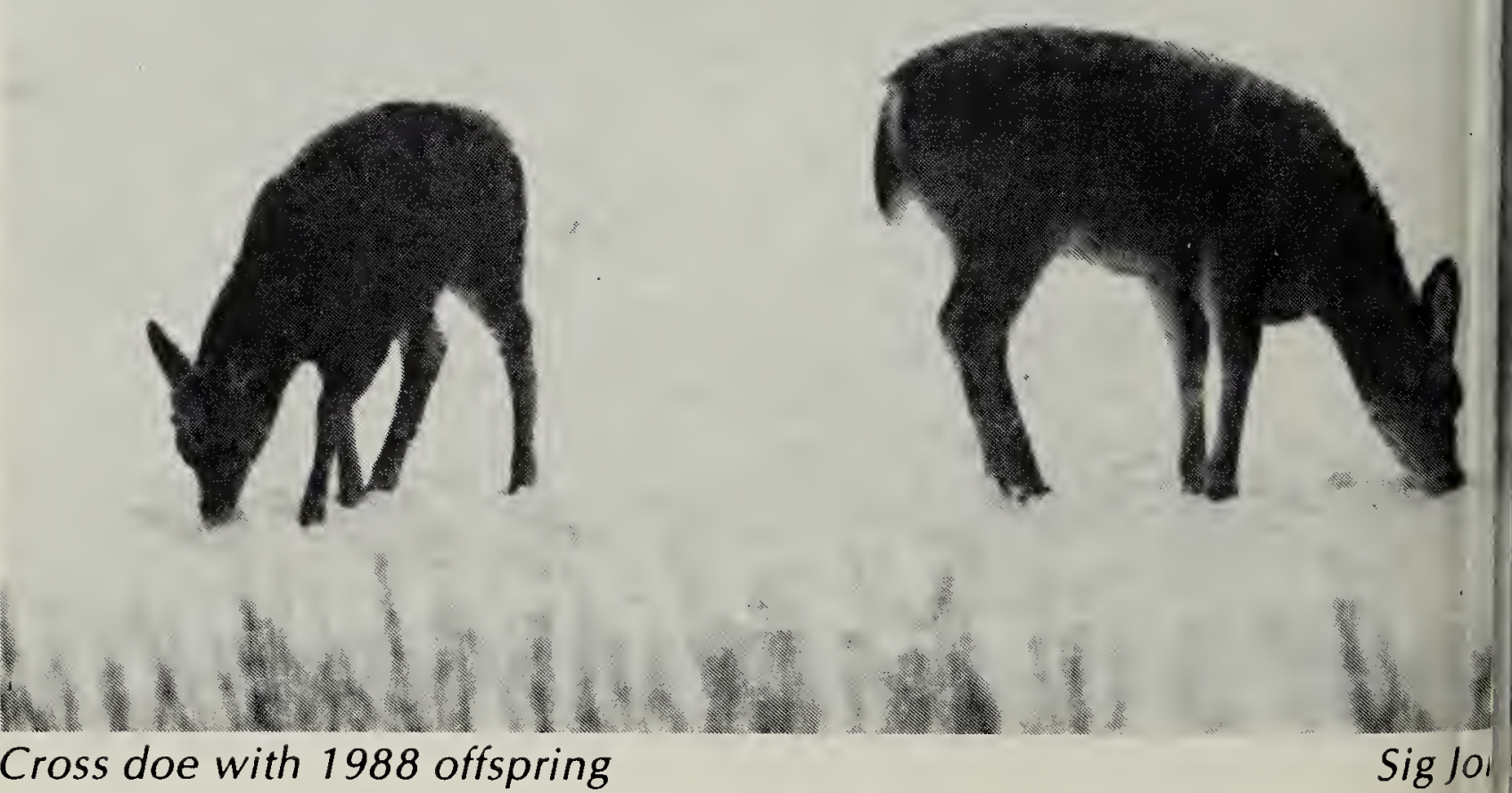

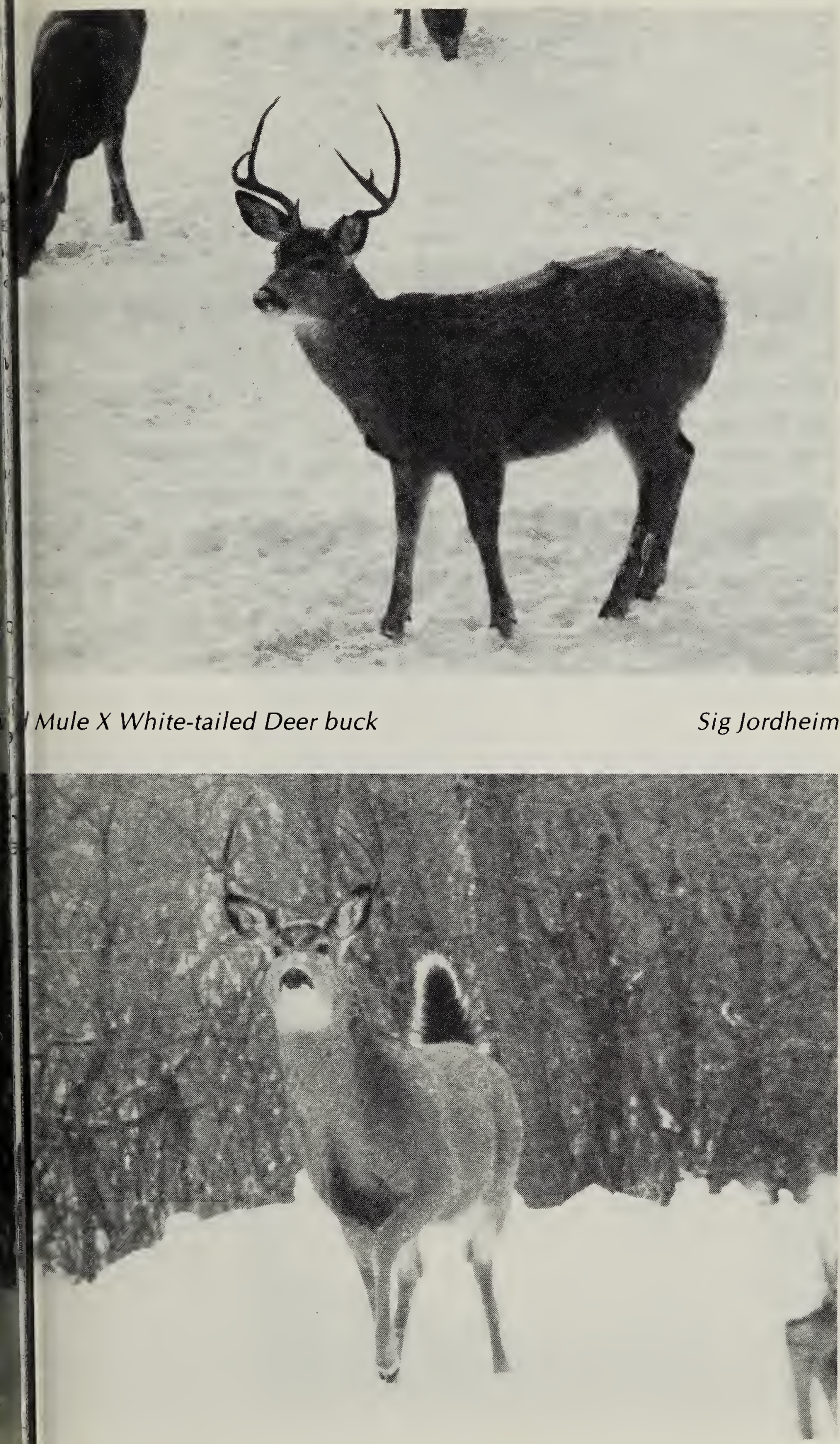